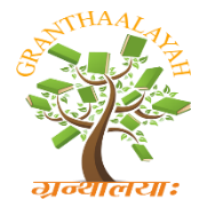

\author{
INTERNATIONAL JOURNAL OF RESEARCH - \\ GRANTHAALAYAH \\ A knowledge Repository
}

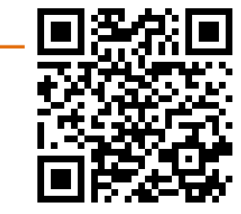

Science

\title{
EXPERIMENTAL STUDY OF STABILIZED EXPANSIVE SOIL USING PUMICE MIXED WITH LIME FOR SUBGRADE ROAD CONSTRUCTION
}

\author{
Robel Tewelde Mesfun ${ }^{* 1}$, Prof. Emer Tucay Quezon ${ }^{* 2}$, Anteneh Geremew ${ }^{3}$ \\ ${ }^{1}$ Civil Engineering Department, Dire Dawa Institute of Technology, Dire Dawa, Ethiopia \\ ${ }^{2}$ Civil \& Construction Engineering and Management Streams, Institute of Technology, Ambo \\ University, P.O Box. 019, Ambo, Oromia Region, Ethiopia \\ 3 Highway Engineering Stream, Jimma Institute of Technology, Jimma University, Ethiopia
}

\begin{abstract}
Unsuitable soil materials along the alignment of road projects have a significant influence on planning, design, construction, and maintenance. Expansive soils are susceptible to considerable volume changes due to seasonal variations and moisture content. Most soils found in Jimma and Ambo Zones composed of plastic clay soil, causing severe damage at the intermittent of pavement sections. This research study conducted laboratory investigation considering combinations of materials blended to stabilize the expansive soil for subgrade construction. An experimental type of study performed which started by collecting specimens. Two clayey soil specimens considered to test the free swell index obtained from a depth of $1.5 \mathrm{~m}$ to remove the organic impurities. Results indicated the chemical analysis of pumice contained $82.68 \%$, while its physical properties of the test of fineness specific surface and residue on 45 microns showed $3770 \mathrm{~cm}^{2} / \mathrm{gm}$ and $30 \%$, respectively. As the lime content increased, the CBR strength also increased. But, if the percent content of lime decreased with an increasing pumice content, the CBR value did not show any significant increase. Both the chemical and physical properties satisfied the requirements according to ASTM C-618. Hence, this experiment obtained $7 \%$ lime $+3 \%$ pumice as an optimum mix ratio to stabilize expansive soils.
\end{abstract}

Keywords: Expansive Soil; Lime; Plastic Clay Soil; Pumice; Stabilization Methods.

Cite This Article: Robel Tewelde Mesfun, Prof. Emer Tucay Quezon, and Anteneh Geremew. (2019). "EXPERIMENTAL STUDY OF STABILIZED EXPANSIVE SOIL USING PUMICE MIXED WITH LIME FOR SUBGRADE ROAD CONSTRUCTION." International Journal of Research - Granthaalayah, 7(7), 118-124. 10.29121/granthaalayah.v7.i7.2019.736.

\section{Introduction}

The long-term performance of any structures depends on the soundness of the underlying soils. Unstable or expansive soils can create significant problems for pavements or structures [1]. Expansive soils in construction sites have a significant influence on planning, structural design, 
construction, maintenance costs, performance and engineering life, especially for shallow foundation structures. It is susceptible to considerable volume changes with response to fluctuations in groundwater table and moisture content following seasonal climatic variations. This behavior of soils can cause severe damages to infrastructure unless proper measures are taken in the design and construction phases [2].

Pavement design based on the premise that minimum specified structural quality could be achieved for pavement material in the system. Each pavement layer must resist shearing, avoid excessive deflections that cause fatigue cracks in the layer, and prevent excessive permanent deformation. As the quality of a soil layer improves, the ability of that layer to distribute the load over a greater area increase; so that a reduction in the required thickness of the soil and surface layers may be permitted. Commonly, improvement attained from soil stabilization can be summarized [3,17]. Frequently used methods of stabilizing weak soils are mechanical compaction or by chemical treatments. Pozzolana is a siliceous or alumina-siliceous material in finely divided form. The presence of moisture chemically reacts at ordinary room temperature with calcium hydroxide, produced by the hydration and reaction of Portland cement, to form compounds possessing cementitious properties [4]. However, Pozzolanic material does not possess a cementing property of its own, but it contains alumina and silica in reactive form. Ancient Romans produced exceptional cement by mixing Pozzolanic materials with lime to build structures, some of which are still standing today [5]. The Pozzolanic reactions are composed of silica reactions in the presence of calcium hydroxide and water to produce calcium silicate hydrates $(\mathrm{C}-\mathrm{S}-\mathrm{H})$ [6,7]. C-S$\mathrm{H}$ created a denser microstructure that increases material strength, reduces the permeability of concrete, and improves its resistance to chemical attack. The addition of Pozzolana reduced pore sizes and porosity leading to increase of strength [18]. In Ethiopia, raw materials of the natural Pozzolanic materials are locally available over a long stretch and wide area of the Rift Valley. On the other hand, Pumice is a kind of glass formed and not a mixture of minerals. Pumice is a lightcolored highly vesicular glass generally composed of $60-70 \% \mathrm{SiO}_{2}, 12-14 \% \mathrm{Al}_{2} \mathrm{O}_{3}, 1-2 \% \mathrm{Fe}_{2} \mathrm{O}_{3}$ and alkali oxides, with a specific gravity of $<1 \%$ [8].

In this research study, a laboratory experiment carried out to investigate the properties of stabilizing expansive soils using pumice mixed with lime for subgrade in road construction. Several issues addressed, such as the swelling and shrinking behavior of expansive soil, cause significant damage to pavement layers. This defect can be attributed to moisture fluctuations caused by seasonal variations. Volumetric changes weaken the subgrade by inducing cracks to the overlying pavement layers. In the study area, expansive soil composed of Montmorillonite-rich clays, over-consolidated clays, and shale's [9]. Engineering problems related to expansive soils have been reported in many countries comprise of about 3\% of the world land area, but are generally mostly located in arid and semi-arid regions. Consequently, many engineering structures suffered severe distress and damages. Cracked foundations, pavement, and basement walls are typical typed of damage due to swelling of soils. Every year, expansive soils cause billions of dollars in damages $[10,11]$. These problems are extensively occurring in Ethiopia. The aerial coverage of expansive soils in Ethiopia is estimated to be 24.7 million acres [12, 13]. It is widely spread in the central part of Ethiopia following the major trunk roads like Addis-Ambo, AddisWolliso, Addis- Debrebirhan, Addis-Gohatsion, and Addis-Modjo. Also, areas like Mekele and Gambella are covered by expansive soils. Soil stabilization is the alteration of one or more soil parameters property by mechanical or chemical treatments, to create an improved soil material 
possessing the desired engineering properties. The process includes the blending of soils to achieve a desired gradation or mixing of commercially available additives that may alter the gradation sizes, texture or plasticity, or act as a binder for cementation of the soil $[3,20]$.

The expansive soils within Jimma Town contain a high Plasticity index and low CBR value; causing unstable subgrade soil which affects the upper pavement layers. In this study, the researchers established an approach to identify the chemical and physical properties of pumice and properties of expansive clay soil in Jimma, as well as strength determination of stabilized expansive soil with pumice and lime.

\section{Materials and Methods}

\subsection{Materials}

Laboratory works conducted at Jimma Institute of Technology, Civil Engineering laboratory, and Ethiopian Roads Authority (ERA) Jimma district laboratory. Hydrated lime collected from Senkele Lime Factory, while Pumice requested from the Dangote Cement Factory. It was known that the Cement Factory extracted raw materials from Meki quarry site.

\subsection{Study Area}

The study area is located more or less $354 \mathrm{kms}$ Southwest of Addis Ababa. The geographical location of the town is approximately $7^{\circ} 41^{\prime} \mathrm{N}$ Latitude and $36^{\circ} 50^{\prime} \mathrm{E}$ Longitude. The town has a temperature of $20^{\circ} \mathrm{C}-30^{\circ} \mathrm{C}$ with an average annual rainfall $800 \mathrm{~mm}-2500 \mathrm{~mm}$. The town is located in an area of the altitude of $1718 \mathrm{~mm}-2000 \mathrm{~m}$ above mean sea level. It lies in the climatic zone locally known as Woynā Dagā, which is considered ideal for agriculture as well as human settlement [15].

\subsection{Sample Data Collection}

Eight subgrade soil specimens collected from different kebeles in Jimma town [10]. From those specimens, by observation, only two clayey soils selected to test its free swell index. The $1^{\text {st }}$ sample gathered from Shenen Gibe Hospital(SGH) along Seka road approximately located at 7³9'24.2" $\mathrm{N}$ Latitude and $36^{\circ} 50^{\prime} 43.2^{\prime \prime}$ E Longitude, and the $2^{\text {nd }}$ sample from Hermata Mentina (HM) kebele along the road to Jimma Aba Jiffar Airport approximately located at 740'19.6" N Latitude and 36 49'26.6" E Longitude [14]. Disturbed samples collected at a depth $1.5 \mathrm{~m}$ below the soil surface.

\subsection{Sampling Technique}

The sampling technique utilized for this research was a purposive sampling, which is non probability method. This sampling technique used, based on the information to determine the strength of the expansive clay soil. 


\section{Results and Discussions}

\subsection{Laboratory Result of the Chemical Properties of Pumice Sample}

Laboratory test results on chemical properties of pumice indicated within the range based on ASTM C-618. The X-ray fluorescence result showed Pozzolanic property of the Pumice. The chemical analysis of pumice resulted with the total compound content of Silicon Dioxide $\left(\mathrm{SiO}_{2}\right)$, Aluminum Oxide $\left(\mathrm{Al}_{2} \mathrm{O} 3\right)$ and Iron Oxide $\left(\mathrm{Fe}_{2} \mathrm{O}_{3}\right)$ of $82.68 \%$, which was above the minimum of $70 \%$ as per ASTM C-618. It means the material was a good Pozzolan. The Pumice sample had a cementitious compound like calcium oxide, alumina, and iron oxide with a total of about $15.90 \%$.

Table1: Test results on chemical composition of pumice

\begin{tabular}{|l|l|l|l|}
\hline No. & Chemical Composition & Test Results (\%) & Requirement ASTM - 618 (\%) \\
\hline 1 & $\left(\mathrm{SiO}_{2}+\mathrm{AI}_{2} \mathrm{O}_{3}+\mathrm{Fe}_{2} \mathrm{O}_{3}\right)$ & 82.68 & 70 (min.) \\
\hline 2 & $\mathrm{SiO}_{2}$ & 68.39 & 35 (min.) \\
\hline 3 & $\mathrm{AI}_{2} \mathrm{O}_{3}$ & 7.62 & \multirow{2}{*}{ N.a } \\
\hline 4 & $\mathrm{Fe}_{2} \mathrm{O}_{3}$ & 6.67 & \\
\hline 5 & $\mathrm{CaO}$ & 1.61 & 5 (max.) \\
\hline 6 & $\mathrm{MgO}$ & 0 & 3 (max.) \\
\hline 7 & Moisture Content & 2.7 & \\
\hline
\end{tabular}

\subsection{Laboratory Test Results for the Physical Property of Pumice Sample}

The fineness specific surface of the pumice indicated $3770 \mathrm{~cm}^{2} / \mathrm{gm}$ and a residue of $30 \%$ in 45 microns in a wet sieve. The test result fulfilled the requirements according to ASTM C-618. Hence, it is acceptable to use as a mineral admixture in cement.

Table 2: Test results on physical properties of pumice

\begin{tabular}{|l|l|l|l|}
\hline No. & Characteristics & Test results (\%) & Requirement as per ASTM C618, (\%) \\
\hline 1 & Fineness specific surface & 3770 & $3200($ min.) \\
\hline 2 & Residue on 45 microns & 30 & 34 (max.) \\
\hline
\end{tabular}

\subsection{Geotechnical Properties of Soil Sample}

The HM and SGH soil samples changed from liquid state to the plastic state and indicated an average liquid limit of $90 \%$ and $106 \%$, respectively. As a result, at this stage, all the soil specimens possessed a certain small shear strength. This arbitrarily chosen shear strength was probably the smallest value that is feasible to measure in a standardized procedure. The given soil sample translated from plastic state to a semi-solid state and obtained with an average plastic limit of 36\% and $37 \%$ for HM and SGH soil samples. From the Atterberg's limit test results, the Plasticity Index of the two specimens indicated 54\%, and 69\%, respectively. Generally Liquid limit less than 35\% are low plasticity, between $35 \%$ and $50 \%$ intermediate plasticity, between $50 \%$ and $70 \%$ high plasticity and between $70 \%$ and $90 \%$ very high plasticity [16]. Hence, the results showed that both soil samples are very high plastic clay. It means, the behavior of the subgrade soils will shrink and swell easily, and cannot resist the internal and external loads, a tendency of creating cracks in the pavement structures. One of the remedies to stop such failure, stabilization of expansive soils prior 
to the sub-base, base and surfacing layers, different additives are necessary.

The CBR test determined at 2.54 and 5.08 penetration at the given maximum dry density, and optimum moisture content in both soil samples. The soil sample (HM) had $0.8 \%$ soaked CBR value at a maximum dry density with $0.17 \%$ CBR swell, while the soil sample (SGH) had $0.91 \%$ CBR value with $0.21 \%$ CBR swell. Results for both soil samples indicated low CBR values. The subgrade soils are not suitable for road construction as per ERA Standard Specifications. It means both soil samples were expansive soils, and it required additives to stabilize. To achieve the objective of this study, both soil samples (MH \& SGH) were stabilized using pumice and lime minerals.

\subsection{Laboratory Test Results of Stabilized Expansive Clay Soil}

\subsubsection{Atterberg Limits}

The amount of pumice mixed with lime was added at the different ratio to the expansive clay soil to reduce the plasticity index of the soil. The Pozzolanic reaction is dependent on both access to water, Pozzolanic materials, and content of calcium ions, and there is not enough calcium in pumice. It means a certain amount of calcium content of lime is necessary. The Plasticity index values of untreated samples (i.e., HM and SGH) determined in the laboratory indicated 54\% and $69 \%$, respectively. Both samples had PI values in the range of high plasticity index. By the addition of $10 \%$ Lime content for both samples, the PI values decreased to $4 \%$ and $13 \%$.

\subsubsection{Compaction Characteristics}

The effect of the stabilizers of maximum dry density and optimum moisture content of the expansive soil is illustrated in figure 1. The results of optimum moisture content and maximum dry density showed as the stabilization lime proportion increased, the optimum moisture content also increased, but resulted in a decrease of maximum dry density. It means the amount of lime added did not result in a significant change in the optimum moisture content and maximum dry density.

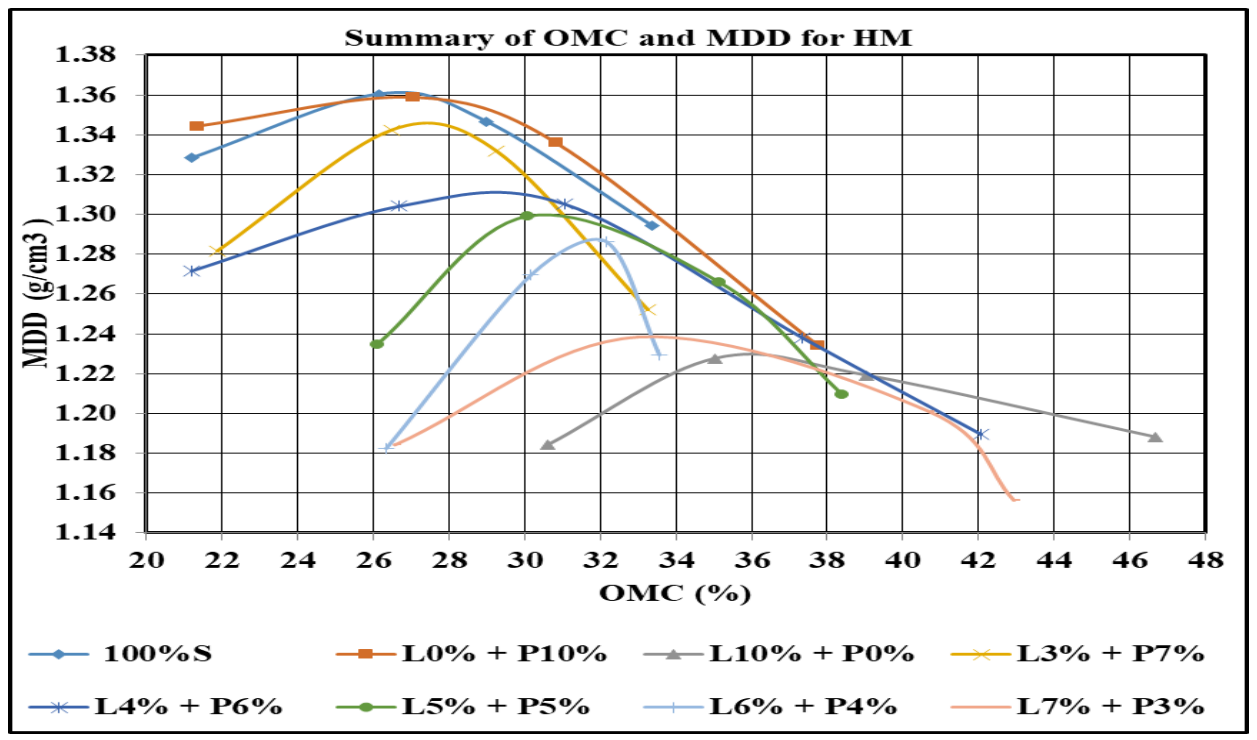

Figure 1: Summary of OMC and MDD of hydrated lime mixed with pumice for HM. 
However, the addition of hydrated lime and pumice at varying contents showed significant changes for optimum moisture content and maximum dry density of expansive soils. This effect caused by cation exchange and short-term Pozzolanic reactions between the lime and the soil resulted in flocculation and agglomeration of clay particles leading to textural changes. These results are inconsistently obtained by Afes and Didier (2000).

\subsubsection{CBR Test Result}

The CBR increased with an increasing lime content than increasing pumice content. A slight improvement has been observed when pumice alone added to the soil. The reason was due to the inadequate amount of calcium required for the formation of Calcium - Silicate - Hydrates (CSH), which is the major element of strength gain. Pumice could be used in admixture stabilization with more potent stabilizers, such as lime and cement, to reduce the cost of stabilization.

\subsubsection{CBR Swell Test Result}

The decrease in CBR Swell of expansive soil resulted in cation exchange, flocculation, and agglomeration of the soil particles. Also, due to the replacement of some volume parts that was previously occupied by expansive clay minerals by pumice. This indicated the soil sample when $10 \%$ pumice added it reduced to a CBR swell value of $0.21 \%$. There was a slight reduction in CBR swell. When the same sample mixed with hydrated lime, it improved the strength of expansive soil. Likewise, a 7\% lime content and 3\% pumice, the CBR swell resulted in $0.03 \%$. This mixed ratio showed the swell potential of the expansive soil reduced, providing a strong bond within the particles. Hence, using both the stabilizers improved the stability and strength of the subgrade soils. It is known, the strength of the subgrade is the principal factor in determining the thickness of the pavement layers. The subgrade strength is associated with the CBR value.

\section{Conclusion}

Based on the laboratory test results of this experiment, the following conclusions are drawn:

- The physical properties and chemical composition of the natural pumice materials indicated $3770 \mathrm{~cm}^{2} / \mathrm{gm}$ fineness specific surface, and $82.68 \%$ respectively. Hence, it satisfied the requirement of ASTM - 618, which was adequate to meet for Pozzolanic materials.

- The test results showed that both subgrade soils considered for this study, under the soil classification A-7-5 as per AASHTO, and $\mathrm{CH}$ in USCS. The Plasticity index for HM sample obtained $54 \%$ and $69 \%$ for SGH sample. Also, the laboratory results for both samples indicated MDD of $1.362 \mathrm{~g} / \mathrm{cm}^{3}$ and $1.298 \mathrm{~g} / \mathrm{cm}^{3}$, respectively. More so, the soaked CBR value of $\mathrm{HM}$ and SGH samples revealed $0.8 \%$ and $0.9 \%$. It indicates the engineering properties of the natural soil samples as expansive clay soil. Both soil samples have a high plasticity index, very low load-bearing capacity, and high swelling potential, and these properties showed the subgrade soil unsuitable to be used for road alignment without additives and stabilizers.

- Adding 10\% Pumice alone produced Plasticity index of 47\% for Hermata Mentina (HM) kebele sample, and $56 \%$ for Shenen Gibe Hospital (SGH), of which indicated a small reduction. Pumice alone had a slight reduction in plasticity index, CBR, free swell Index 
and did not improve the strength of soils due to the presence of reactive silica with a low amount of calcium content in pumice material.

- The optimum moisture content increased, while the maximum dry density decreased with an increasing lime content, and decreasing pumice content. The addition of lime mixed with pumice improved the CBR value. While, a combination of pumice and lime, strongly improve the strength of the expansive soil rather than lime or pumice alone. Therefore, the laboratory test results considering 7\% lime and 3\% pumice indicated a soaked CBR value for $\mathrm{HM}$ sample of $8.2 \%$, and $6.2 \%$ for SGH sample satisfy the ERA Standard Specifications.

\section{References}

[1] NLA, Lime treated soil construction manual, Lime stabilization, and Lime modification, Bulletin: National Lime Association, January 2004.

[2] Chen, F.H., Foundation on expansive soils. Elsevier, Amsterdam, 1988.

[3] Guyer, J. P., Introduction to Soil Stabilization in Pavements. New York, 2011.

[4] Canadian Standards Association, CAN/CSA A3000-98 in Cementitious Materials Compendium. 2000, p. 193.

[5] Chengzhi Z., Aiqin W., Mingshu T., and Xiaoyu L; Cement and Concrete Research. 26(6), 943947, 1996.

[6] Hewlett P., Lea's Chemistry of Cement and Concrete. 4th, Ed., Elsevier. London, 2004.

[7] Jackson, M., Sagnotti, L., Rochette, P., and Sølheid, P., The IRM Quarterly. pp. 13(3), 112, 2003.

[8] Day, Robert L., Pozzolans, for use in low-cost housing. A State of the Art Report Prepared for the International Development Research Center, Ottawa, Canada, 1990.

[9] Nelson, D., and Miller, J., Expansive Soils Problems and Practices in Foundation and Pavement Engineering. New York, 1992.

[10] Jemal J., In-depth Investigation into Engineering Characteristics of Jimma soils. MSc Thesis, Addis Ababa University, Ethiopia, 2014.

[11] Sachim N., Bhavsar, Ankit J., Effect of waste material on swelling and shrinkage properties of clayey soil. International Journal of application or innovation in Engineering \& Management (IJAIEM), vol. 3 (11), 2014, pp. 200-2006.

[12] Lyon Associates, Inc, Laterite and Lateritic soils and other problem soils of Africa. Baltimore, 1971.

[13] Nebro, D., Stabilization of Potentially Expansive Subgrade Soil Using Lime and Con-Aid. MSc. Thesis, Addis Ababa University, Addis Ababa, 2002.

[14] "www.Google map.com," 2017. [Online].

[15] GSE, Geology, Geochemistry, and Gravity Survey of Jima area. 2012.

[16] Whitlow, R., Basic Soil Mechanics, 3rd, Ed., Addison Wesley Longman limited: Edinburgh Gate, 1995.

[17] Department of US Army, Soil Stabilization for Pavements. 1994.

[18] Mindess S., Young J. F. and Darwin, D, Concrete., 2nd, Edition. London: Prentice-Hall, 2003.

\footnotetext{
*Corresponding author.

E-mail address: robinsun2112@gmail.com/quezonet09@gmail.com
} 